\title{
Do health care professionals' perceptions help to measure the degree of overcrowding in the emergency department? A pilot study in an Italian University hospital
}

\author{
Andrea Strada ${ }^{1}$, Francesca Bravi ${ }^{2}$, Giorgia Valpiani ${ }^{2 *}$ (D, Roberto Bentivegna ${ }^{3}$ and Tiziano Carradori ${ }^{4}$
}

\begin{abstract}
Background: Overcrowding in emergency departments (EDs) is internationally recognized as one of the greatest challenges to healthcare provision. Numerous studies have highlighted the ill-effects of overcrowding, including increased length of stay, mortality and cost per admission. This study measures overcrowding in EDs through health care professionals' perceptions of it, comparing the results with the NEDOCS score, an objectively validated measurement tool and describing meaningful tools and strategies used to manage ED overcrowding.

Methods: This single-centre prospective, observational, pilot study was conducted from February 19th to March 7th, 2018 at the ED in the University Hospital of Ferrara, Italy to measure the agreement of the NEDOCS, comparing objective scores with healthcare professionals' perception of overcrowding, using the kappa statistic assessing linear weights according to Cohen's method. The tools and strategies used to manage ED overcrowding are described.

Results: Seventy-two healthcare professionals (66.1\% of 109 eligible subjects) were included in the analyses. The study obtained a total of 262 surveys from 23 ED physicians (31.9\%), 31 nurses (43.1\%) and 18 nursing assistants (25.0\%) and a total of 262 NEDOCS scores. The agreement between the NEDOCS and the subjective scales was poor $(k=0.381,95 \% \mathrm{Cl} 0.313-0.450)$.
\end{abstract}

Conclusions: The subjective health care professionals' perceptions did not provide an adequate real-time measure of the current demands and capacity of the ED. A more objective measure is needed to make quality decisions about health care professional needs and the ability to manage patients to ensure the provision of proper care.

Keywords: Emergency department, Crowding, Healthcare professionals' perceptions, Perception overcrowding, NEDOCS, Case management, Flow manager

\section{Background}

High demand and need for emergency department (ED) services has been reported worldwide [1, 2]. Indeed, ED overcrowding is increasingly recognized as a global public health problem $[3,4]$. Overcrowding in the ED can be the result of several factors, such as entry or "input" problems,

\footnotetext{
* Correspondence: giorgia.valpiani@ospfe.it

${ }^{2}$ Research Innovation Quality and Accreditation Unit, S. Anna University Hospital of Ferrara, Via Aldo Moro 8, (1A3 stanza 3.41.40), 44124 Ferrara, Cona, Italy

Full list of author information is available at the end of the article
}

internal factors related to "throughput" and exit or "output" bottleneck problems [4]. The delays in transferring patients to hospital wards once triaged and assessed in the ED appear to be an important cause of ED overcrowding, leading to boarding of patients in the ED [5]. Other factors such as the emergence of new healthcare needs, an ageing population, an increasing number of patients with complex cases and the advent of new diagnostic technologies may also contribute to ED overcrowding [6]. For instance, certain subsets of patients have an increased likelihood of boarding in the ED, such as women, elderly patients and

(c) The Author(s). 2019 Open Access This article is distributed under the terms of the Creative Commons Attribution 4.0 International License (http://creativecommons.org/licenses/by/4.0/), which permits unrestricted use, distribution, and reproduction in any medium, provided you give appropriate credit to the original author(s) and the source, provide a link to the Creative Commons license, and indicate if changes were made. The Creative Commons Public Domain Dedication waiver (http://creativecommons.org/publicdomain/zero/1.0/) applies to the data made available in this article, unless otherwise stated. 
patients with severe medical conditions, such as pneumonia or cardiac insufficiency [7]. Regardless of the underlying reason, ED overcrowding can lead to negative patient outcomes, such as possible delays in access to care and diagnosis and increased mortality for patients transferred to hospital wards (for both adult and paediatric patients) and for those discharged from the ED [8, 9]. Placing patients on stretchers in corridors with little privacy, where basic needs such as food and personal hygiene cannot be guaranteed, can also negatively affect a patient's satisfaction with the care that they receive $[10,11]$. Working in such adverse conditions may also compromise public and staff security. Furthermore, there is a high probability of staff "burn-out", increasing the risk of conflict and further compromising the quality of care [10-14].

Overcrowding has led institutions and health care providers to seek more efficient ways to rapidly administer patient care and make better use of ED waiting times. Several countries, such as the United Kingdom, Canada, Australia and New Zealand, have attempted to reduce overcrowding through dedicated regulatory and managerial interventions. Standards have been defined for maximum duration of stay in the ED (4-6h), maximum wait time for transfer to a hospital department $(2 \mathrm{~h})$, incentives/sanctions for healthcare companies, revision of patients' hospitalization programmes, centralized management of hospital resources and the development of pre-hospitalization/pre-discharge units [15-18].

In Italy, the structure of the emergency/urgency network is defined by the Ministerial Decree and includes emergency call centres as well as territorial assistance and hospital networks. At the local level, healthcare companies may adopt more flexible guidelines to provide more efficient management of hospital beds in periods of high ED use. In any given year, more than a third ( 24 million) of the Italian population visits their local ED, and up to $20 \%$ of these visits result in hospitalization. ED visits by patients with more complex medical problems have also increased over the years. Those aged 80 and over accounted for $8 \%$ of visits in 2005, 10\% in 2010 and $12 \%$ in 2015. The National Statistics Institute (ISTAT) reported an approximately $60 \%$ increase in the aged visiting the ED during this time period, and further increases have been predicted over time, from 1.3 million in 2007 to 4.8 million in 2050. Data for the Emilia-Romagna Region of Northeast Italy are similar to those nationwide. Yearly ED visits have been stable from 2014 to 2015, 2016, and 2017 $(1,861,000,1,857,137,1,875,560$ and $1,891,005$, respectively), as have admissions per year (approximately 13\%), although there appears to be a steady increase in the time spent by patients in the ED [19].

Several ED crowding estimation tools have been developed and deployed [20-24]. Among these is the National
Emergency Department Overcrowding Scale (NEDOCS), which is widely used in the USA [23], as well as in the ED of hospitals in the Emilia Romagna Region [19]. The goal of this study was to measure overcrowding in emergency departments through health care professionals' perception of it, comparing the results with the NEDOCS score, an objectively validated measurement tool. The goal of this study is to measure overcrowding in emergency departments through health care professionals' perception of it, comparing the results with the NEDOCS score, an objectively validated measurement tool. The secondary objective is to describe meaningful tools and strategies used to manage ED overcrowding in our University Hospital.

\section{Methods}

This was a single-centre prospective, observational, pilot study. The study was conducted at the Emergency Department in the University Hospital of Ferrara, located in the Emilia-Romagna Region, with a hospital catchment area catering to approximately 340,000 inhabitants. The network has a hub \& spoke structure; the hub for STEMI and STROKE is located in the S. Anna University Hospital (Ferrara), and the spokes are community hospitals (Mazzolani Vandini Hospital located in Argenta, SS. Annunziata Hospital located in Cento and Delta Hospital located in Lagosanto, all in the Emilia-Romagna Region). This study covered a sample period of 28 days from February 19th to March 7th, 2018 (study period). The first stage of this study involved data analysis of the NEDOCS scoring tool in determining overcrowding status.

\section{Assessing overcrowding in the ED}

The NEDOCS score is the total of seven variables recorded at a single point in time and entered into a formula to generate the score [25]. These included, as fixed values, 25 ED beds and 528 hospital beds for adults and children, reflecting the installed capacity. The other values used for the score were total patients in the ED, total number of requested hospital admissions from the $\mathrm{ED}$, number of respirators in the ED, longest admission time and waiting room time for the last patient called. The NEDOCS score was calculated every hour at realtime points during the study period and graded as follows: $0-20$ not busy, $21-60$ busy, $61-100$ extremely busy but not overcrowded, 101-140 overcrowded, 141-180 severely overcrowded and 181-200 dangerously overcrowded [23]. The NEDOCS score was compared to the subjective evaluation of ED overcrowding (perceived ED crowding) by the ED staff (physicians, nurses and nursing aides/nursing assistants) Questionnaires were administered by a student/trainee and included the following variables: time at which the questionnaire was answered, role (physician, nurse, nursing assistant), and an index of perception of ED overcrowding rated on a $0-10 \mathrm{~cm}$ 
Visual Analogue Scale (VAS) [26]. The latter reflected the respondent's level of "feeling rushed" or "pressured" at that particular point in time. The questionnaire was administered twice per shift for three daily shifts (8:0014:00, 14:00-20:00, 20:00-8:00) during the period from February 19 to March 7, 2018. For comparison purposes with the results of the NEDOCS scale, each individual VAS score was multiplied by 20 , as suggested by Weiss et al. [24]. The perception of overcrowding was graded as follows: $0-40=$ not busy, $40-80=$ busy, $80-120=$ extremely busy, not overcrowded, $120-160=$ overcrowded, $160-200=$ severely overcrowded, and $\geq 200$ dangerously overcrowded. The NEDOCS and perceived overcrowding scales were administered during the same time period. The staff participating in the study had over two years of experience working in the ED. Healthcare professionals absent for health reasons (illness, pregnancy, etc.) or on holiday during the study period were also excluded.

\section{Statistical analysis}

The results were expressed as the means and standard deviations (SD) for normally distributed data and as medians and interquartile ranges [1Q 3Q] for skewed data. Categorical variables were summarized using counts and percentages. Quantitative variables were compared among the three healthcare professional groups by an analysis of variance followed by the application of a multiple comparison test or non-parametric Kruskal-Wallis test. Bonferroni correction was used for multiple comparisons. Chi-squared or, when at least one expected frequency in a fourfold table was less than five, the Fisher's Exact test were performed to compare categorical variables (VAS and NEDOCS score graded into six classes, including "not busy", "busy", "extremely busy, not overcrowded", "overcrowded", "severely overcrowded", "dangerously overcrowded") from among groups (physicians, nurses, nursing assistant). Non-parametric Spearman coefficients $\left(r_{s}\right)$ were calculated to measure the correlation between the two overcrowding measures. The concordance between the overcrowding classification derived from NEDOCS score and healthcare professionals' crowding perceptions using the six-point VAS scale was evaluated in each ED using unweighted and weighted Cohen's kappa coefficient and the corresponding 95\% confidence interval $(95 \% \mathrm{CI})[27,28]$. The weights assigned were calculated according to Cohen's method using linear weights $\left(\kappa_{\mathrm{w}}\right)$ [29]. The $\mathrm{k}$-coefficient interpretation was performed on the basis of the study by Landis and Koch [30]. The following levels of agreement were considered appropriate for judging the extent of the agreement: $\kappa$ less than 0.0 , poor; $0.0 \leq \kappa \leq 0.2$, slight; $0.21 \leq \kappa \leq 0.4$, fair; $0.41 \leq \kappa \leq 0.6$, moderate; $0.61 \leq \kappa \leq$ 0.80 , substantial; and $\kappa$ more than 0.80 , almost perfect.
Statistical analysis was performed using the statistical package for the social sciences (IBM Corp., IBM SPSS Statistics for Windows, Version 23.0 Armonk, New York USA). We also used the VassarStats website program for Statistical Computation to calculate concordance measurements (http://vassarstats.net/kappa.html). A two-sided value of $p \leq 0.05$ was considered statistically significant.

\section{Results}

During the study period, 2298 patients attended the ED. Demographic characteristics of these patients and the distribution of emergency colour codes are shown in Table 1. A total of 109 subjects were eligible for the survey: 72 healthcare professionals $(66.1 \%)$ were included in the analyses, while 37 (33.9\%), including 14 physicians, 18 nurses and 5 nursing assistants, did not meet the inclusion criteria. Those who had less than two years' work experience in the ED (12 physicians, 18 nurses and 3 nursing assistants) or who were absent for health reasons (illness, pregnancy, etc.) or on holiday (2 physicians and 2 nursing assistants) were excluded. The study obtained a total of 262 surveys from 23 ED physicians (31.9\%), 31 nurses (43.1\%) and 18 nursing assistants (25.0\%) and a total of 262 NEDOCS scores. Table 2 reports demographic characteristics, years of work data and NEDOCS and VAS scores in the healthcare professional groups included in the analyses.

The nurses were younger than the physicians and nursing assistants $(p<0.001)$ and therefore had a shorter median time of work experience than the other groups. The median values of the NEDOCS scores in the three groups showed low statistical significance $(p=0.057)$. Highly significant differences emerged, however,

Table 1 Demographic characteristics of patients in the ED during the study period and distribution of colour $\operatorname{codes}^{a}$

\begin{tabular}{lll}
\hline & & Patients \\
\hline \multirow{3}{*}{ Gender } & female & 2298 \\
& male & $1119(48.7)$ \\
Age (yrs.) & mean ( \pm SD) & $1179(51.3)$ \\
& female & $61(22)$ \\
male & $63(22)$ \\
Colour code & $59(21)$ \\
& red & \\
& yellow & $87(3.8)$ \\
& green & $820(35.7)$ \\
white & $1306(56.8)$ \\
\hline
\end{tabular}

${ }^{a}$ The colour code is given to establish the priority of access to treatment based on the seriousness of the case. Red code: very critical, danger of death, maximum priority, immediate access to treatment; yellow code: fairly critical, high level of risk, potential danger of death; treatment cannot be delayed; green code: not very critical, no risk of condition worsening, treatment can be delayed; white code: not critical, not serious and/or not acute 
Table 2 Demographic, work data and NEDOCS and VAS scores in the three healthcare professional groups involved in the survey

\begin{tabular}{|c|c|c|c|c|c|}
\hline & & $\begin{array}{l}\text { Physicians } \\
\mathrm{N}=23 \\
(31.9 \%)\end{array}$ & $\begin{array}{l}\text { Nurses } \\
\mathrm{N}=31 \\
(43.1 \%)\end{array}$ & $\begin{array}{l}\text { Nursing assistants } \\
\mathrm{N}=18 \\
(25.0 \%)\end{array}$ & $\begin{array}{l}\quad \text { Total } \\
N=72 \\
(100 \%)\end{array}$ \\
\hline Gender (female)† & $n(\%)$ & $11(47.8)$ & $20(64.5)$ & $10(55.6)$ & $41(56.9)$ \\
\hline Age $($ yrs.) $\neq$ & $\begin{array}{l}\text { mean }( \pm S D) \\
\min -\max \end{array}$ & $\begin{array}{l}53.3(8.4) \\
36-65\end{array}$ & $\begin{array}{l}43.8(9.1) \\
30-65\end{array}$ & $\begin{array}{l}53.9(4.0) \\
45-59\end{array}$ & $\begin{array}{l}49.3(9.1) \\
30-65\end{array}$ \\
\hline Experience working in the ED (yrs.) $\neq$ & $\begin{array}{l}\text { median }[1 Q 3 Q] \\
\min -\max \end{array}$ & $\begin{array}{l}15\left[\begin{array}{ll}9 & 17] \\
2-26\end{array}\right.\end{array}$ & $\begin{array}{l}12\left[\begin{array}{ll}8 & 26\end{array}\right] \\
2-35\end{array}$ & $\begin{array}{l}26\left[\begin{array}{ll}21 & 32.8\end{array}\right] \\
16-35\end{array}$ & $\begin{array}{l}16\left[\begin{array}{ll}10 & 26\end{array}\right] \\
2-35\end{array}$ \\
\hline NEDOCS score \# & $\begin{array}{l}\text { median } \\
\text { [1Q 3Q] }\end{array}$ & $\begin{array}{l}70 \\
{\left[\begin{array}{ll}53.5 & 128.8\end{array}\right]}\end{array}$ & $\begin{array}{l}121 \\
{\left[\begin{array}{ll}69 & 162.8\end{array}\right]}\end{array}$ & $\begin{array}{l}103 \\
{\left[\begin{array}{ll}72.5 & 148.5\end{array}\right]}\end{array}$ & $\begin{array}{l}112.5 \\
{\left[\begin{array}{ll}67.8 & 156\end{array}\right]}\end{array}$ \\
\hline VAS score $\S$ & $\begin{array}{l}\text { median } \\
{[1030]}\end{array}$ & $\begin{array}{l}40 \\
{[0} \\
{[115]}\end{array}$ & $\begin{array}{l}100 \\
{\left[\begin{array}{ll}60 & 160\end{array}\right]}\end{array}$ & $\begin{array}{l}100 \\
{\left[\begin{array}{ll}60 & 160\end{array}\right]}\end{array}$ & $\begin{array}{l}100 \\
{[40160]}\end{array}$ \\
\hline
\end{tabular}

SD: standard deviation; [1Q 3Q] interquartile range; ED: emergency department; † $p=$ n.s.; $\neq p<0.001 ; \# p=0.057 ; \S p=0.002$

between the median values of healthcare professionals' perceptions of overcrowding $(p=0.002)$. A positive correlation $\left(\mathrm{r}_{\mathrm{s}}=0.614, p \leq 0.001\right)$ was found between the objective NEDOCS scale and the subjective scale representing all healthcare professionals. A summary of the extent of concordance between the subjective healthcare professionals' scale and the NEDOCS score was generated by category and is presented in Table 3. Analysis of the data showed a $28.2 \%$ overall concordance with a linear weighted kappa index of 0.381 . This indicates poor concordance between the two categorical scores. Nurses had a higher perception of ED overcrowding than physicians and nursing assistants $\left(\kappa_{\mathrm{w}}=\right.$ 0.403 CI 95\% 0.313; 0.493).

Figure 1 compares the distribution of the two 6-point scales, NEDOCS and VAS, and stratifies the objective scale according to categories of healthcare professionals. When the ED was "not busy" or "busy", the healthcare professionals tended to overestimate the level of overcrowding; in the case of the ED being "not busy", the difference was statistically significant, particularly for physicians vs nurses and nursing assistants $(p<0.001)$. An examination of the last three classes of overcrowding suggests that the NEDOCS overestimates the subjective values of the healthcare professionals, which, for the "overcrowded" class, have virtually identical values $(14 \%$ physicians, $15 \%$ nursing assistant and 15\% nurses). Regarding "seriously overcrowded" and "dangerously overcrowded" classes, physicians had a lower (not statistically significant) perception of overcrowding than nurses
(7\% physicians vs. 15\% nurses for "seriously overcrowded" and $4 \%$ physicians vs. $15 \%$ nurses for "dangerously overcrowded"). Nurses' and nursing assistants' perceptions did not show statistically significant differences in situations of dangerous overcrowding conditions.

\section{Discussion}

Improved tools for early predictors of ED overcrowding could assist EDs and hospital administrators in implementing near-real-time interventions. The NEDOCS score is one tool that is used in Emilia Romagna Region (Italy) and has been found to assess ED overcrowding with relatively high consistency [23]. Overcrowding is considered a perception and can change according to different healthcare professionals' experience. This study showed little concordance between ED healthcare professionals' perceived assessments and the NEDOCS score of an overcrowded ED. In general, no common agreement exists between the subjective perception of health care professionals and the objective tool used to measure ED overcrowding [31,32]. The subjective health care professionals' perceptions do not provide an adequate real-time measure of the current demands and capacity of the ED. Although health care professionals' perceptions may provide some useful information, a more objective measurement is needed to make quality decisions about the health care professionals' needs and the ability to manage patients to ensure the provision of proper care. The values of the subjective healthcare professionals' perception were not in agreement with the objective NEDOCS scale,

Table 3 Concordance between the subjective scale (VAS) and objective scale (NEDOCS) by healthcare professionals

\begin{tabular}{|c|c|c|c|c|}
\hline & \multicolumn{2}{|c|}{ Proportions of concordance } & \multirow{2}{*}{$\begin{array}{l}\text { Unweighted } \\
\text { Kappa }(95 \% \text { Cl) }\end{array}$} & \multirow{2}{*}{$\begin{array}{l}\text { Kappa with Linear } \\
\text { Weighting ( } 95 \% \mathrm{Cl})\end{array}$} \\
\hline & Observed $(95 \% \mathrm{Cl})^{a}$ & Change expected & & \\
\hline All healthcare professionals & $0.282(0.2300 .342)$ & 0.174 & $0.131(0.0650 .197)$ & $0.381(0.3130 .450)$ \\
\hline Physicians & $0.250(0.1140 .452)$ & 0.162 & $0.105(0.0 .266)$ & $0.366(0.2130 .518)$ \\
\hline Nurses & $0.281(0.2110 .362)$ & 0.173 & $0.131(0.0420 .220)$ & $0.403(0.3130 .493)$ \\
\hline Nursing assistants & $0.296(0.2050 .404)$ & 0.187 & $0.133(0.0190 .248)$ & $0.302(0.1680 .436)$ \\
\hline
\end{tabular}




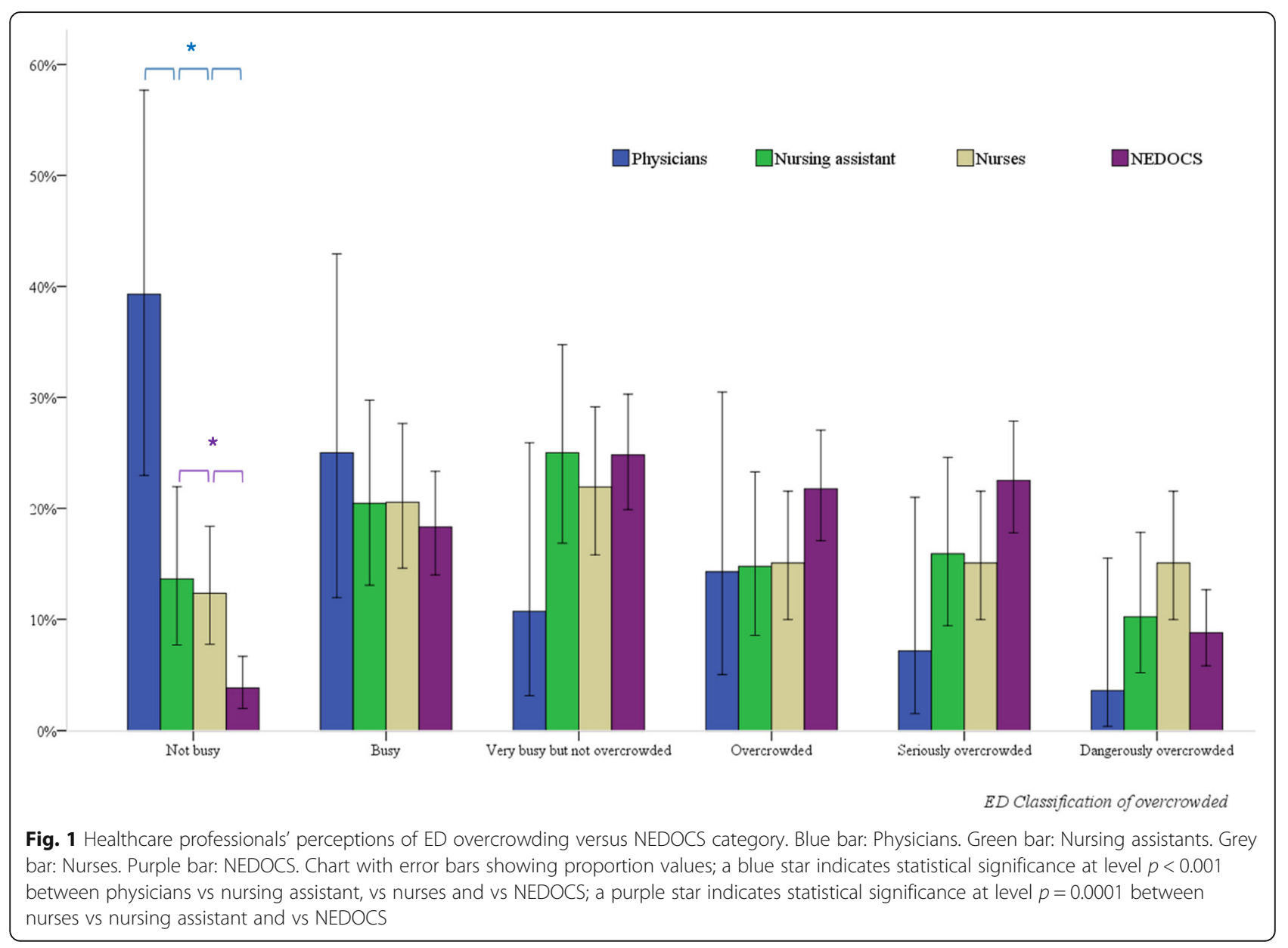

particularly when the latter was categorized as "overcrowded" and "seriously overcrowded". The nurses' perception of overcrowding was better correlated to the objective scale than the physicians' perception. This may be because nurses are in closer contact with the needs of the ED and with all the patients, including patients waiting to be treated as well as those waiting to be transferred to a hospital bed. In our study, the physicians felt less "rushed" than the nurses when the EDs were overcrowded, but we did not find a correlation between healthcare professionals' perceptions and the NEDOCS classification of overcrowding, even when the scales were completed during maximum overcrowding.

Emergency department crowding represents an international crisis that may affect the quality and access to health care. Our solutions to overcrowding include the implementation of a new organizational model to improve hospital "responsiveness" [33].

\section{Patient flow management in the emergency department}

The ED organizational model has been re-examined, and specific monitoring of emergency department functioning has been established, paying particular attention to access, flow and treatment times. Tools and the strategies used to manage ED crowding are described in the Hyperflow management plan (Table 4). The fluidity of the intake pathways for the different priority codes, green, yellow and red will be closely examined. This will be under the supervision of a Flow Manager (FM), an experienced nurse responsible for managing patients pre triage, periodically re-examining their clinical conditions in synergy with the clinical-healthcare team and, when necessary, redefining priority codes. Post-triage will also be a concern as the FM would constantly review and redefine priorities in accessing medical care. Furthermore, the FM can improve outflow by acting as the interface between the ED and the various specialized outpatient clinics, the hospital Bed Managers (BM) and maintaining a good working relationship with the spoke hospitals of the metropolitan area. BM facilitate correct and swift allocation of patients in the appropriate care settings by checking and controlling activation of the availability of suitable beds. Case Managers (CM) are involved in the planned discharge of patients from the ED, assessing the potential risks and difficulties that this process might incur [34]. 


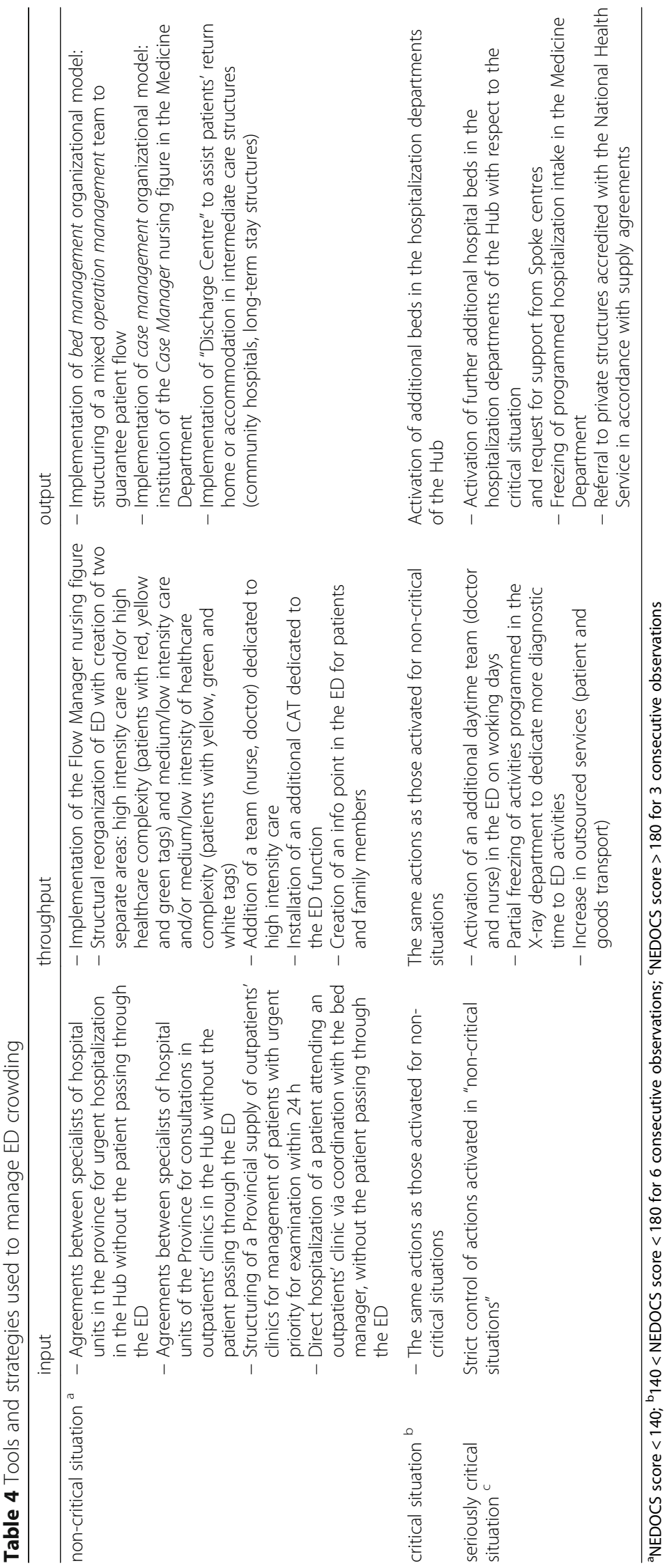


The Post-Discharge Follow-Up Centre (Centrale di Dimissione Continuità Assistenziale - CDCA) by interacting with primary care and social services, is tasked with activating codified pathways for complex discharges. The CDCA takes factors such as the number of patients awaiting discharge and the total number of occupied hospital into account, helping to safeguard hospital bed resources in the HUB as well as essential services.

The BM, the CM and the CDCA are in constant communication as they share the same objectives of simplifying and facilitating incoming patient flows (patient - in), ensuring continuity of care during hospital admission (patient - stay) and easing outflow, and maintaining and guaranteeing suitable continuity of care and assistance (patient - out). The communicative interfaces of the BM are the ED doctors, the CM, the CDCA and the Medical Department doctors.

\section{Case management}

The $\mathrm{CM}$ is a nurse possessing extensive knowledge of the services and organizational structures of the HUB and primary healthcare. The $\mathrm{CM}$ ensures appropriate and swift management of hospitalized patients with a view to their ongoing healthcare and facilitated discharge in a suitable primary care setting with proper information. The CM, through updated and precise awareness of the situation of patients held for recovery in the Medical Department, facilitates the use of tools and resources for the planning of discharges. The CM draws on the collaboration of clinical nurses suitably trained to become aware of patients with discharge difficulties and rapidly activates the social/healthcare services of primary care. In such cases, the professionals advise the CM swiftly (24-48 $\mathrm{h}$ from hospitalization or as soon as possible) whenever the following occur:

- The hospitalized patient is not self-sufficient, or is likely not to be so following the severe episode in progress, and lives alone or with a fragile family member;

- The patient is a frequent user of hospital structures;

- The patient is accepted by the University Hospital for "social hospitalization";

- The patient is a guest in a residential structure but is no longer in a condition to return to it;

- The patient is already known to the Home Assistance Services or the Social Services, for which the reason for hospitalization constitutes a worsening of their fragile condition;

- The patient has no fixed address.

The Case Manager refers to the BRASS Index Scale1 for early assessment of a difficult discharge case. The Case Manager interfaces with the professionals in charge of the patient's case to achieve a planned discharge and simultaneously observe caregivers' needs for therapeutic education in relation to family members' conditions and the need to activate aids or devices at home. In the case of necessity, the Case Manager supports activation through the formal structured channels of the CDCA of suitable multidimensional assessments. The Case Manager maintains an ongoing and structured interface with the Bed Manager, informing the latter of the state of discharges from the hospital departments.

\section{Conclusion}

Our results indicate a poor agreement of health care professionals' perceptions and NEDOCS score that seems to overestimate the subjective values of the healthcare professionals. Our study outcomes indicate that the NEDOCS might not be a suitable tool to determine ED crowding in an academic ED setting, and more objective measurements could be needed to make quality decisions about health care professional needs and the ability to manage patients to ensure the provision of proper care. A larger multicentre study among similar ED environments is required to achieve external validation.

\section{Abbreviations}

BM: Bed Manager; CDCA: Centrale di Dimissione Continuità Assistenziale; Cl: Confidence Interval; CM: Case Manager; ED: Emergency Department; FM: Flow Manager; ISTAT: The National Statistics Institute; NEDOCS: National ED Overcrowding Study; NEDOCS: National Emergency Department

Overcrowding Scale; SD: Standard Deviations; VAS: Visual Analogue Scale

\section{Acknowledgements}

The authors would like to thank all physicians, nursing staff and nursing assistants of the emergency department participating in the study. Special thanks are due to nursing staff managers, Catia Crepaldi and Antonella Pesci, who helped organize and supervise the validation data collection. The authors would also like to thank Elena Forini (Health statistics office at Ferrara University Hospital) for providing useful suggestions for the planning of the survey and Gianmarco Funaro, student trainee in statistics at University of Bologna, who helped in collecting and transferring the raw data in electronic files.

\section{Statement}

This manuscript contains original material that has not previously been published or submitted to any other journal.

\section{Author's contributions}

We certify that all individuals who qualify as authors have been listed; each of us has participated in one or more of the following areas: 1) conception and design of this work (AS; FB); 2) acquisition and/or analysis and interpretation of data (GV; FB); 3) writing or critical revision of the document (TC: RB); and 4) supervision of this cooperative research effort (FB;GV). All contributing authors approve of the submission of this version of the document and assert that it represents valid work. All contributing authors take public responsibility for this work.

Funding

Not applicable

Availability of data and materials

Not applicable

Ethics approval and consent to participate Not applicable 


\section{Consent for publication}

Not applicable

\section{Competing interests}

The authors declare that there is no conflict of interest regarding the publication of this paper.

\section{Author details}

${ }^{1}$ Emergency-Urgency Medicine Department, S. Anna University Hospital of Ferrara, Ferrara, Italy. ${ }^{2}$ Research Innovation Quality and Accreditation Unit, S. Anna University Hospital of Ferrara, Via Aldo Moro 8, (1A3 stanza 3.41.40), 44124 Ferrara, Cona, Italy. ${ }^{3}$ Medical Direction Department, S. Anna University Hospital of Ferrara, Ferrara, Italy. ${ }^{4}$ S. Anna University Hospital of Ferrara, Ferrara, Italy.

\section{Received: 5 February 2019 Accepted: 1 August 2019} Published online: 27 August 2019

\section{References}

1. Drummond AJ. No room at the inn: overcrowding in Ontario's emergency departments. CJEM. 2002 Mar; 4 (2):91-97. PubMed PMID: 17612426.

2. Trzeciak S, Rivers EP. Emergency department overcrowding in the United States: an emerging threat to patient safety and public health. Emerg Med J. 2003 20(5):402-405. Review. doi: https://doi.org/10.1136/emj.20.5.402 PubMed PMID: 12954674.

3. Hoot NR, Aronsky D. Systematic review of emergency department crowding: causes, effects, and solutions. Ann Emerg Med 2008; 52(2):126136. doi: https://doi.org/10.1016/j.annemergmed.2008.03.014. Epub 2008 Apr 23. Review. PubMed PMID: 18433933

4. Di Somma S, Paladino L, Vaughan L, Lalle I, Magrini L, Magnanti M. Overcrowding in emergency department: an international issue. Intern Emerg Med 2015;10 (2):171-175. doi: https://doi.org/10.1007/s11739014-1154-8. Epub 2014 Dec 2. PubMed PMID: 25446540.

5. van der Linden N, van der Linden MC, Richards JR, Derlet RW, Grootendorst $D C$, van den Brand CL. Effects of emergency department crowding on the delivery of timely care in an inner-city hospital in the Netherlands. Eur J Emerg Med 2016;23(5):337-343. doi: https://doi.org/10.1097/MEJ. 0000000000000268. PubMed PMID: 25831039.

6. Patterson BW, Pulia MS, Ravi S, Hoonakker PLT, Schoofs Hundt A, Wiegmann D, Wirkus EJ, Johnson S, Carayon P. Scope and Influence of Electronic Health Record-Integrated Clinical Decision Support in the Emergency Department: A Systematic Review. Ann Emerg Med. 2019. doi:https://doi org/10.1016/j.annemergmed.2018.10.034. [Epub ahead of print] PubMed PMID: 30611639

7. Hodgins MJ, Moore N, Legere L. Who is sleeping in our beds? Factors predicting the ED boarding of admitted patients for more than 2 hours. J Emerg Nurs 2011; 37(3):225-230. doi: https://doi.org/10.1016/j.jen.2010.02.02 0. Epub 2010 Mar 31. PubMed PMID: 21550454.

8. Pines JM, Hilton JA, Weber EJ, Alkemade AJ, Al Shabanah H, Anderson PD, Bernhard M, Bertini A, Gries A, Ferrandiz S, Kumar VA, Harjola VP, Hogan B, Madsen B, Mason S, Ohlén G, Rainer T, Rathlev N, Revue E, Richardson D, Sattarian M, Schull MJ. International perspectives on emergency department crowding. Acad Emerg Med 2011; 18(12):1358-1370. doi: https://doi.org/1 0.1111/j.1553-2712.2011.01235.x. Review. PubMed PMID: 22168200.

9. Timm NL, Ho ML, Luria JW. Pediatric emergency department overcrowding and impact on patient flow outcomes. Acad Emerg Med 2008; 15(9):832837. doi: https://doi.org/10.1111/j.1553-2712.2008.00224.x. PubMed PMID: 18821860.

10. Moskop JC, Sklar DP, Geiderman JM, Schears RM, Bookman KJ. Emergency department crowding, part 1--concept, causes, and moral consequences. Ann Emerg Med 2009; 53 (5):605-611. doi: https://doi.org/10.1016/j. annemergmed.2008.09.019. Epub 2008 Nov 22. Review. PubMed PMID: 19027193.

11. Moskop JC, Sklar DP, Geiderman JM, Schears RM, Bookman KJ. Emergency department crowding, part 2--barriers to reform and strategies to overcome them. Ann Emerg Med 2009; 53 (5):612-617. doi: https://doi.org/10.1016/j. annemergmed.2008.09.024. Epub 2008 Nov 22. Review. PubMed PMID: 19027194

12. Barishansky RM, O'Connor KE. The effect of emergency department crowding on ambulance availability. Ann Emerg Med 2004; 44:280-281. PubMed PMID: 15332307.
13. Barrett TW, Schriger DL. Annals of emergency medicine journal Club. Emergency department crowding is associated with poor care for patients with severe pain. Ann Emerg Med 2008;51(1):6-7. doi: https://doi.org/10.1 016/j.annemergmed.2007.11.022. PubMed PMID: 18166434

14. Bernstein SL, Aronsky D, Duseja R, Epstein S, Handel D, Hwang U, McCarthy M, John McConnell K, Pines JM, Rathlev N, Schafermeyer R, Zwemer F, Schull M, Asplin BR; Society for Academic Emergency Medicine, emergency department crowding task force. The effect of emergency department crowding on clinically oriented outcomes. Acad Emerg Med 2009; 16 (1):110. doi: https://doi.org/10.1111/j.1553-2712.2008.00295.x. Epub 2008 Nov 8. Review. PubMed PMID: 19007346.

15. Weber EJ, Mason S, Freeman JV, Coster J. Implications of England's four-hour target for quality of care and resource use in the emergency department. Ann Emerg Med 2012; 60(6):699-706. doi: https://doi.org/10.1016/j.annemergmed.2 012.08.009. Epub 2012 Oct 23. PubMed PMID: 23102917.

16. Vermeulen MJ, Guttmann A, Stukel TA, Kachra A, Sivilotti ML, Rowe BH, Dreyer J, Bell R, Schull M. Are reductions in emergency department length of stay associated with improvements in quality of care? A difference-indifferences analysis. BMJ Qual Saf 2016; 25(7):489-498. doi: https://doi.org/1 0.1136/bmjqs-2015-004189. Epub 2015 Aug 13. PubMed PMID: 26271919; PubMed Central PMCID: PMC4941160.

17. Jones PG, Olsen S. Point prevalence of access block and overcrowding in New Zealand emergency departments in 2010 and their relationship to the 'Shorter stays in ED' target. Emerg Med Australas 2011;23(5):587-592. doi: https://doi.org/10.1111/j.1742-6723.2011.01451.x. Epub 2011 Jun 27. PubMed PMID: 21995473.

18. Geelhoed GC, de Klerk NH. Emergency department overcrowding, mortality and the 4-hour rule in Western Australia. Med J Aust. 2012;196:122-6 Erratum in: Med J Aust. 2012 Mar 5; 196(4):245. PubMed PMID: 22304606.

19. Delibera 1827 del 17/11/2017. Linee di indirizzo alle Aziende Sanitarie per la gestione del sovraffollamento nelle strutture di Pronto Soccorso della Regione Emilia-Romagna https://bur.regione.emilia-romagna.it/dettaglio-inserzione?i= e8add067b5664058bd668d524acdc32c (last accessed 24 Jan 2019).

20. Stang AS, Crotts J, Johnson DW, Hartling L, Guttmann A. Crowding measures associated with the quality of emergency department care: a systematic review. Acad Emerg Med 2015; 22 (6):643-656. doi: https://doi.org/10.1111/ acem.12682. Epub 2015 May 20. Review. PubMed PMID: 25996053.

21. Wang H, Robinson RD, Garrett JS, Bunch K, Huggins CA, Watson K, Daniels J,Banks B, D'Etienne JP, Zenarosa NR. Use of the SONET score to evaluate high volume emergency department overcrowding: a prospective derivation and validation study. Emerg Med Int 2015; 2015: 401757. doi: https://doi.org/10.1155/2015/401757. Epub 2015 Jun 8. PubMed PMID: 26167302; PubMed Central PMCID: PMC4475699.

22. Wang H, Ojha RP, Robinson RD, Jackson BE, Shaikh SA, Cowden CD, Shyamanand R,Leuck J, Schrader CD, Zenarosa NR. Optimal Measurement Interval for Emergency Department Crowding Estimation Tools. Ann Emerg Med. 2017;70 (5):632-639.e4. doi: https://doi.org/10.1016/j.annemergmed.2 017.04.012. Epub 2017 Jul 6. PubMed PMID: 28688771.

23. Weiss SJ, Derlet R, Arndahl J, et al. Estimating the degree of emergency department overcrowding in academic medical centers: results of the national ED overcrowding study (NEDOCS). Acad Emerg Med. 2004;1 1:38-50.

24. Bernstein SL, Verghese $V$, Leung $W$, et al. Development and validation of a new index to measure emergency department crowding. Acad Emerg Med. 2003;10:938-42

25. Boyle A, Abel G, Raut P, Austin R, Dhakshinamoorthy V, Ayyamuthu R, Murdoch I, Burton J. Comparison of the international crowding measure in emergency departments (ICMED) and the National Emergency Department Overcrowding Score (NEDOCS) to measure emergency department crowding: pilot study. Emerg Med J 2016; 33(5):307-312. doi: https://doi.org/10.1136/emermed-2 014-203616. Epub 2016 Jan 6. PubMed PMID: 26739294

26. Wewers ME, Lowe NK. A critical review of visual analogue scales in the measurement of clinical phenomena. Res Nurs Health 1990;13(4):227-236. Review. PubMed PMID: 2197679.

27. Cohen J. A coefficient of agreement for nominal scales. Educ Psychol Meas. 1960;20:213-20.

28. Fleiss $\mathrm{J}$, Cohen J, Everitt BS. Large sample standard errors of kappa and weighted kappa. Psychol Bull. 1969;72:323-7.

29. Cohen J. Weighted kappa: normal scale agreement with provision for scaled disagreement or partial credit. Psych Bulletin. 1968;6:213-20.

30. Landis JR, Koch GG. The measurement of observer agreement for categorical data. Biometrics. 1977;33:159-74. 
31. Garcia-Romero M, Rita-Gáfaro CG, Quintero-Manzano J, Angarita AB. NEDOCS vs subjective evaluation, Is the health personnel of the emergency department aware of its overcrowding Colomb Med (Cali) 2017; 48(2):5357. PubMed PMID: 28924304; PubMed Central PMCID: PMC5597093.

32. Reeder TJ, Burleson DL, Garrison HG. The overcrowded emergency department: a comparison of staff perceptions. Acad Emerg Med 2003; 10(10):1059-1064. PubMed PMID: 14525738.

33. The World Health Report. Health systems: improving performance. Geneva: World Health Organization; 2000. https:/www.who.int/whr/2000/en/ (last accessed 24 Jan 2019)

34. Improta G, Romano M, Di Cicco MV, Ferraro A, Borrelli A, Verdoliva C, Triassi M, Cesarelli M. Lean thinking to improve emergency department throughput at AORN Cardarelli hospital. BMC Health Serv Res. 2018;18(1): 914. https://doi.org/10.1186/s12913-018-3654-0.

\section{Publisher's Note}

Springer Nature remains neutral with regard to jurisdictional claims in published maps and institutional affiliations.

Ready to submit your research? Choose BMC and benefit from:

- fast, convenient online submission

- thorough peer review by experienced researchers in your field

- rapid publication on acceptance

- support for research data, including large and complex data types

- gold Open Access which fosters wider collaboration and increased citations

- maximum visibility for your research: over $100 \mathrm{M}$ website views per year

At BMC, research is always in progress.

Learn more biomedcentral.com/submissions 